\title{
TELEVISÃO PÚBLICA E DIREITOS HUMANOS: UMA ANÁLISE DA PROGRAMAÇÃO DA TV BRASIL E SEU PAPEL NA DIFUSÃO E NA PRO- MOÇÃO DO DEBATE AFIRMATIVO SOBRE A DECLARAÇÃO UNIVERSAL DOS DIREITOS HUMANOS
}

WALDELIO PINHEIRO DO NASCIMENTO JÚNIOR UNIVERSIDADE FEDERAL DAPARAÍBA JOÃO PESSOA, PARAÍBA,BRASIL E-MAIL: JUNIORPINHEIRO@YMAIL.COM HTTP://DX.DOI.ORG/10.5902/2316882X22060 
TELEVISÃO PÚBLICA E DIREITOS HUMANOS: UMA ANÁLISE DA PROGRAMAÇÃO DA TV BRASIL E SEU PAPEL NA DIFUSÃO E NA PROMOÇÃO DO DEBATE AFIRMATIVO SOBRE A DECLARAÇÃO UNIVERSAL DOS DIREITOS HUMANOS Resumo: A mídia hegemônica relega a segundo plano o diálogo com as ações afirmativas, minorias identitárias e direitos humanos. Por outro lado, a televisão pública desponta como ambiente propício para promover a valorização e o respeito à diversidade. Nos últimos anos, a TV Brasil produziu e veiculou programas voltados à temática, alguns dos quais são objetos de análise deste estudo, cujo intuito é analisar o papel da tevê pública na formação cidadã em direitos humanos.

Palavras chave: Direitos Humanos; Televisão Pública; Cidadania; Diversidade; Minorias.

LA TELEVISIÓN PÚBLICA Y LOS DERECHOS HUMANOS: UN ANLISIS DE LA PROGRAMACIÓN DE TV BRASIL Y SU PAPEL EN LA DIFUSIÓN Y PROMOCIÓN DEL DEBATE AFIRMATIVO EN LA DECLARACIÓN UNIVERSAL DE DERECHOS HUMANOS

Resumen: Los medios de comunicación relegan a un segundo plano el diálogo con la acción afirmativa, las minorías de identidad y los derechos humanos. Por otra parte, la televisión pública se está convirtiendo en el medio propicio para promover la apreciación y el respeto por la diversidad. En los últimos años, la TV Brasil produjo y transmitió programas destinados a tema, algunos de los cuales son objeto de análisis de este estudio, cuyo objetivo es analizar el papel de la televisión pública en la formación de la ciudadanía e los derechos humanos.

Palabras clave: Derechos Humanos; Televisión Pública; Ciudadanía; Diversidad; Minorías.

PUBLIC TELEVISION AND HUMAN RIGHTS: AN ANALYSIS OF THE PROGRAMMING OF TV BRAZIL AND ITS ACTING IN THE DISSEMINATION AND PROMOTION OF AFFIRMATIVE DISCUSSION ON THE UNIVERSAL DECLARATION OF HUMAN RIGHTS

Abstract: The mainstream media relegates to the background the dialogue with affirmative action, identity minorities and human rights. On the other hand, public television is emerging as environment conducive to promoting the appreciation and respect for diversity. In recent years, the TV Brazil produced and aired programs aimed issue, some of which are objects of analysis of this study, which aims to analyze the acting of public TV in civic education on human rights.

Keywords: Human Rights; Public Television; Citizenship; Diversity; Minorities. 


\section{INTRODUÇÃO}

A temática da comunicação pública, na última década, voltou a ocupar importantes espaços, tanto no cenário sociopolítico quanto acadêmico, no Brasil. Em parte, tal fato se deve ao desenvolvimento de um projeto, em nível nacional, de um sistema público de comunicação, bem como das ações decorrentes do mesmo. Neste ínterim, uma das discussões pertinentes ao assunto diz respeito ao conceito e papel socioeducativo, político e cultural da comunicação pública.

No Brasil, frequências de rádios e televisão são propriedades da União e, apesar de concedidas à exploração de empresas privadas, não deixam de ser patrimônio público. Assim, possuem regulamentações que, mesmo defasadas, visam assegurar o comprometimento social dos conteúdos produzidos e veiculados por meio da radiodifusão. Contudo, na disputa por audiência e lucro, a mídia costuma violar os códigos legais e éticos, fazendo-se necessária não só intervenção e fiscalização mais incisiva do Estado, como também o fomento à produção e veiculação de programas cujos conteúdos sejam comprometidos com a diversidade sociocultural, com as minorias e com a participação popular, respeitando as alteridades.

O contraponto às programações das tevês comerciais seria a televisão pública. No Brasil, costuma-se diferenciar os meios de comunicação públicos dos demais levando-se em conta a natureza de sua administração, da produção de seu conteúdo e a sua finalidade. Entre as emissoras de televisão, por exemplo, o termo televisão pública é utilizado para designar as tevês vinculadas aos Poderes Executivo, Legislativo e Judiciário, bem como às universidades públicas, fundações culturais e educativas sem fins lucrativos, além de associações comunitárias.

Em todos estes casos, a programação precisa ser diversificada, com informação de qualidade e conteúdos relevantes para a sociedade, capazes de suscitar o pensamento crítico e o compromisso com a cidadania. Pesquisas científicas e produções artísticas e intelectuais encontram espaço ao lado das tradições e folguedos da cultura popular; ou ainda das lutas, desafios e reivindicações das minorias e dos movimentos sociais. Em suma, a televisão pública deve ter uma compreensão diferenciada acerca de seu telespectador, elevando-o da posição de consumidor à de cidadão.

Emissora vinculada ao Poder Executivo, por meio da Empresa Brasil de Comunicação - EBC, a TV Brasil, em atenção às diretrizes estabelecidas pe-

Rev. Cad.Comun, Santa Maria, v.20,n.1, art 1, p.1 de 24, jan/abr.2016 
las políticas governamentais em prol da educação em Direitos Humanos, busca produzir e veicular programas voltados à temática. São produções que visam elucidar os itens da Declaração Universal dos Direitos Humanos, apresentar histórias de luta pela redemocratização do Brasil, ou promover o debate sério e afirmativo com a comunidade. Estes conteúdos não só atendem aos princípios da qualidade em televisão, como também intentam despertar na sociedade o pensamento crítico e cidadão.

\section{DIREITOS HUMANOS E SEUS DESAFIOS, NO CONTEXTO NACIO- NAL}

Nunca se falou tanto em direitos humanos, no Brasil. Escolas, universidades e meios de comunicação revezam-se com os discursos políticos, movimentos sociais e conversas informais do cotidiano, no debate do tema. Infelizmente, nem sempre a qualidade das informações é proporcional ao volume que o assunto vem ganhando - principalmente na mídia.

Ativistas e movimentos têm conseguido junto ao Estado que muitas revindicações presentes em suas pautas sejam levadas em consideração na construção de políticas públicas que sejam eficazes para assegurar que os princípios da Declaração Universal dos Direitos Humanos sejam cumpridos, no Brasil, após séculos de disparidades socioculturais, cujos sintomas foram agravados, especialmente entre os anos de 1964 e 1985, durante a ditadura militar.

Fruto de disputas e aspirações históricas, os direitos humanos surgem a partir do reconhecimento da necessidade de certas condições essenciais para assegurar uma vida plena e digna aos indivíduos, independente de sua etnia, idade, gênero, orientação sexual, crença, convicção política e condição socioeconômica, entre outras características.

Embora a DUDH tenha sido aprovada em dezembro de 1948, durante a Assembleia Geral das Nações Unidas, sua construção se deu por meio de um processo histórico e se baseou em outras cartas e documentos voltados à promoção da igualdade, da liberdade e fraternidade entre os homens. O documento da Organização das Nações Unidas - ONU é um marco, pois ao convocar diversas nações ao compromisso com tais princípios, assinala a internacionalização desses direitos, abrindo espaços para a celebração de outros tratados e convenções internacionais (MOURA, 2014).

O Brasil, além de sua Constituição Cidadã, de 1988, é signatário de um

Rev. Cad.Comun, Santa Maria, v.20,n.1, art 1, p.1 de 24, jan/abr.2016 
amplo conjunto de convenções e tratados internacionais voltados à promoção dos direitos humanos e à construção de uma sociedade justa, solidária e livre da pobreza, da marginalização, dos preconceitos de qualquer espécie e das desigualdades sociais e regionais.

Entretanto, tais condições asseguradas normativamente nem sempre significam sua aplicabilidade real e eficaz. Para percorrer a distância existente entre o campo legislativo e a prática, é necessário um conjunto de ações articuladas que vão desde a criação de políticas públicas e entidades fiscalizadoras até a promoção de ações educativas e criticas.

Neste cenário, a mídia é imprescindível para a promoção de debates e construção da cidadania, por conta de seu poder de penetração e difusão de conteúdos. Infelizmente, tal espaço, que deveria ser sempre plural, diverso e comprometido com o interesse público, é controlado por pouquíssimos grupos, vinculados direta, ou indiretamente, aos poderes políticos e econômicos.

A televisão brasileira está ainda muito distante dos ideais de interesse público e cidadania, que devem nortear uma programação televisual. Programas humorísticos promovem explicitamente o preconceito, o sexismo, o racismo, a homofobia, o desrespeito, a mercantilização e a criminalização de mulheres, negros e homossexuais. Os jornais policiais exploram a desgraça alheia e fazem da miséria humana seu atrativo. Ainda, as emissoras controladas por grupos religiosos fazem forte proselitismo, violando a lei, disseminando preconceitos e não abrindo portas de diálogos com a diversidade de crenças.

Diante da urgência e do desafio dos direitos humanos, no Brasil, o contexto midiático para sua difusão e prática é extremamente desfavorável. Informações manipuladas distorcem os ideais que permeiam a declaração e ignoram a conjuntura histórica e socioeconômica que culminaram nos problemas sociais que o país vivencia hoje. A desinformação veiculada é tamanha, que chega ao ponto de associar a democracia e a defesa dos direitos humanos com apologia à impunidade, à violência criminal e ao crime organizado, afinal, um julgamento justo e oportunidades de ressocialização são benefícios que devem estar disponíveis apenas aos "cidadãos de bem".

Comprometida com a elite moralista e conservadora, tal mídia difunde a ideia de um mundo dividido, onde existem, em lados antagônicos, ordem, honestidade e bons costumes, em contraponto ao caos, à dege-

Rev. Cad.Comun, Santa Maria, v.20,n.1, art 1, p.1 de 24, jan/abr.2016 
neração moral, à promiscuidade, à desonestidade, à violência e à bandidagem. Associando tais condições às classes sociais opostas, são apontados, enquanto vítimas da violência, apenas os grupos mais privilegiados, que trabalham e pagam seus impostos, os quais sofrem atentados seu patrimônio e vida privada.

Estabelece-se um clima de medo e de violência contínua. Aponta-se a ineficiência das forças de segurança pública e a ausência de ações governamentais. $O$ cidadão, refém do medo, é impelido a agir por conta própria, a fim de que a ordem seja restabelecida. A pena de morte, embora não legalizada, torna-se realidade e é tacitamente aceita. O lucro de tais ações não é pequeno e pode advir em vários níveis e setores.

\section{TELEVISÃO, SENSACIONALISMO E VIOLAÇÕES DOS DIREITOS HUMANOS}

A televisão, enquanto meio de comunicação complexo, caro e que depende constantemente de inovações tecnológicas, precisou se adequar à lógica de mercado, a fim de assegurar maior lucro. Enquanto parte de grandes conglomerados comunicacionais, tais emissoras estão em franca concorrência, definida por relações de força não percebidas que podem ser apreendidas por meio de indicadores tais como as fatias de mercado, o prestígio frente aos anunciantes, ou o capital coletivo de profissionais reconhecidos (BOURDIEU, 1997).

Quando as tevês são diretamente dependentes do mercado e a concorrência é a tônica da programação televisual, o índice de audiência é o critério que define o valor de cada conteúdo, bem como de sua inserção comercial. Tal crivo é o que garante, ou não, se um programa terá sucesso de público ou se, em caso contrário, deverá passar por reformulações, ou mesmo ser tirado do ar (BARBOSA, 2010).

Para garantir o maior público possível e o consequente retorno financeiro, as tevês criam programas que atraiam seus telespectadores, por vezes dando preferência ao interesse do público em detrimento do interesse público. Desse modo, em plena era da "ditadura da imagem", da espetacularização da programação e da notícia, um assunto pertinente, mas que não renda imagens sensacionais, será substituído por qualquer outro, mesmo frívolo ou insignificante, mas que seja capaz de render cenas de forte conteúdo emocional.

Rev. Cad.Comun, , Santa Maria, v.20,n.1, art 1, p.1 de 24, jan/abr.2016 
O sensacionalismo, a busca pelo espetáculo, se transformou em pedra angular de diversos programas televisivos. A onda popularesca, que mescla reportagens sobre aberrações com entrevistas que desnudam por completo a intimidade alheia, ocupa, agora, o horário nobre da televisão (BARBOSA, 2010, p. 58).

Para assegurar o sucesso de audiência que se traduza em lucro, as tevês produzem conteúdos que, não raras vezes, acabam por se inclinar para um sensacionalismo explícito, mascarado de interesse público e recheado de moralismos e apelações, cuja estrutura não chega a ser percebida pelos telespectadores. Os apresentadores e jornalistas de tais atrações convertem-se em pequenos diretores de consciência, porta-vozes da opinião pública, ditando o que se deve pensar sobre os problemas da sociedade, só que de forma superficial, banalizada, homogeneizada e, em certa medida, despolitizada, sem se preocupar, de fato, com uma revolução simbólica.

Não só a televisão, mas a comunicação de massa como um todo, interfere nas formas de organização social, nas mais diferentes culturas, não só produzindo outros modelos de sociabilidade, como também interferindo na subjetividade e no imaginário contemporâneo.

A exibição constante de conteúdos brutais ou agressivos, sem a devida reflexão acerca dos mesmos, contribui para a banalização e para o aumento da tolerância à violência. Além disso, como afirma Maria Rita Kehl (2004), ao apresentar o outro enquanto ameaça, incentiva-se medidas agressivas como meio de defesa, como uma resposta a essa ameaça que o outro representa. Por isso, sente-se certo alívio ao ver no ar a cena de algum suspeito, ou criminoso, sendo morto em confronto com a polícia, ou por meio da barbárie da população - muitas vezes incitada por apresentadores sensacionalistas a fazer, com as próprias mãos, “justiça mais rápida e eficaz", que a do Estado. Mesmo diante de imagens brutais, a sociedade pode ficar tranquila: "trata-se de uma ameaça a menos".

Buscam-se heróis, capazes de cumprir a lei, antes que os ativistas dos direitos humanos possam intervir para "proteger o marginal". Procuram-se vinganças, enquanto meio de justiça, repressões e execuções, enquanto forma de se extirpar o mal da sociedade (BUCCl, 2004).

Em tempo, além da necessidade de se mostrar o criminoso morrendo, é preciso mostrar também a polícia matando, diante das câmeras. Tal imagem, sempre associada à competência da ação policial, é muito valorizada e aplaudida pelos apresentadores do jornalismo policial. Na luta do bem

Rev. Cad.Comun, Santa Maria, v.20,n.1, art 1, p.1 de 24, jan/abr.2016 
contra o mal, os policiais "cumpriram seu papel e eliminaram agentes do crime".

Eugênio Bucci (2004) aponta que, nestes casos, o policial é também uma espécie de vítima que, sem entender, por completo, a dimensão de tal mise en scène, é explorado, a serviço do espetáculo. Se tais programas funcionam como anabolizantes da indústria do pânico, também contribuíram para deformar a imagem do policial - inclusive a imagem que ele mesmo tem de seu papel - aumentando a brutalidade dentro da própria polícia.

No outro lado da mesma moeda, os humorísticos, ao se valerem dos estereótipos regionais, do pitoresco e da ridicularização daqueles que não se inserem nos padrões sociais conservadores, esvaziam os debates sobre o respeito às alteridades e as políticas públicas voltadas às populações em situação de risco. Como agravante, mesmo numa análise superficial, percebe-se que a mídia que veicula conteúdos apelativos é a mesma que destina pouquíssimo, ou nenhum, espaço afirmativo para a difusão das lutas e conquistas dos movimentos sociais e minorias.

\section{UMA BREVE ANÁLISE DA REALIDADE TELEVISUAL BRASILEIRA}

Desenvolvida durante o momento de transição entre a ditadura civil-militar e o atual período democrático, a Constituição Federal Brasileira de 1988 buscou atender a princípios e demandas capazes de promover o acesso aos direitos humanos, civis, políticos e sociais, bem como às condições para o exercício pleno da cidadania, ficando, por isso, conhecida como Constituição Cidadã.

Em seu artigo 221, a Carta Magna nacional define as prioridades na programação das rádios e televisões. Obrigatoriamente, tais emissoras, por operarem concessões públicas, têm a obrigatoriedade de produzir e veicular materiais educativos, artísticos, informativos, culturais, que valorizem o regionalismo e as diferenças, bem como que respeitem os valores éticos e sociais da pessoa e da família.

Apesar da regulamentação, cada vez mais conteúdos duvidosos são veiculados nas televisões do país. Numa reação em cadeia, provocada pela concorrência, quanto mais apelativo for o programa veiculado por uma tevê, maiores as chances de ele ser copiado pelas demais.

Na verdade, o sensacionalismo na televisão brasileira não é um pro-

Rev. Cad.Comun, Santa Maria, v.20,n.1, art 1, p.1 de 24, jan/abr.2016 
blema recente. Desde seu início, a tevê incorporou muito da linguagem de outros meios, trazendo profissionais do rádio, do teatro, do cinema e do circo para compor seus quadros. Entre esses, se encontravam artistas de programas humorísticos de baixo nível, bem como redatores e locutores de jornais populares, páginas policiais e programas de rádio de mesma linha.

Em meados dos anos 1960, por exemplo, O Homem do Sapato Branco, veiculado pela TV Globo e apontado por Marco Roxo (2010) como o grande precursor da televisão espetáculo, no Brasil, exibia matérias e entrevistas recheadas de sensacionalismo, baixaria, casos da desgraça humana e exploração da miséria na tevê, contando com grande audiência para a época.

Em 1979, a TV Tupi lançou o Aqui e Agora, cujo intuito era retratar os problemas da periferia urbana, suas dificuldades e reclamações. Tal caráter assistencialista fazia do programa uma espécie de pátio dos milagres, onde doentes e miseráveis tinham a ilusão de resolver, de forma mágica, seus problemas e enfermidades, bastando expô-los na onipotente tevê.

Com a cassação da concessão da Tupi, em 1980, a Bandeirantes adquiriu os direitos do Aqui e Agora, modificando seu formato por conta das pressões contrárias à espetacularização e ao baixo nível da programação, advindas de parte da sociedade e de alguns grupos políticos. Se o programa foi levado para a TV Bandeirantes, boa parte de sua equipe foi contratada por Sílvio Santos para o seu recém-criado Sistema Brasileiro de Televisão - SBT, onde passaram a apresentar O Povo na TV, com formato idêntico ao do seu sucessor da Tupi.

Quando a Globo optou por uma linha de programação que correspondesse aos anseios da classe média em ascensão, retirou do ar muitos programas e artistas considerados apelativos ou popularescos. Sílvio Santos vislumbrou, em tal medida, uma oportunidade de ocupar o espaço em aberto deixado pela emissora carioca, contratando, nos anos 1980, parte do casting demitido (MIRA, 2010). Assim, nos anos 1990, o SBT se torna líder de audiência entre as classes $C$ e $D$, muito por conta de programas populares como A Praça é Nossa e o Aqui Agora, cujo carro-chefe era as exibições, ao vivo, de ações policiais, tiroteios e até suicídios.

Ainda nos anos 1990, as demais emissoras, a fim de competir com o canal de Sílvio Santos, criaram programas policiais similares, como o Cidade Alerta, da TV Record, o Brasil Urgente, da TV Bandeirantes, o 190 Urgente

Rev. Cad.Comun, Santa Maria, v.20,n.1, art 1, p.1 de 24, jan/abr.2016 
da CNT e o Na Rota do Crime, da extinta Manchete, hoje RedeTV!, cuja programação é, quase em totalidade, apelativa e de mau gosto.

Para Luiza Lusvarghi (2007), o processo de popularização da televisão, com a exploração de fatos presumivelmente reais, em programas de auditório ou realities shows, não é um fenômeno apenas brasileiro. Em várias partes do mundo, tal situação se fez notar, a partir dos anos 1980 e está vinculada com o maior acesso aos aparelhos televisores por parte das classes menos favorecidas.

Programas que "lavam a roupa suja" ao vivo, ou que funcionem como uma espécie de consultório onde ocorrem sessões de terapia de grupo para famílias ou vizinhos ganharam cada vez mais espaço, ao lado dos realities shows e dos jornais popularescos, cujos apresentadores adquirem status de estrela, geralmente galgando posições políticas, num momento oportuno, ou sendo disputados por outros canais, trocando de emissoras em negociações milionárias.

Com a programação apelativa atraindo públicos para os outros canais, mesmo a Globo precisou rever sua posição de emissora elitista, a fim de não perder faixas de público que estavam migrando para as demais emissoras. No fim dos anos 1980 e nas décadas posteriores, a tevê do Jardim Botânico apostou em programas popularescos, humorísticos de gosto duvidoso e realities shows apelativos.

\section{TELEVISÃO PÚBLICA NO BRASIL}

Na contramão do ocorrido em países como Inglaterra, França e Alemanha - onde o Estado foi o responsável pela implantação e regulação da televisão - no Brasil a tevê foi trazida e controlada, em seu início, pela iniciativa privada, seguindo o modelo de negócios já praticado pelos conglomerados comunicacionais existentes no país. Nos anos 1950, quando o novo meio aporta em terras tupiniquins, o país vivenciava um período de mudanças em sua estrutura social, econômica e política, demarcado pelos investimentos em infraestrutura, modificações nas relações de trabalho e industrialização, o que ocasionou um grande movimento de migração do campo para as grandes cidades (MATTOS, 2000).

Quando os militares assumiram o governo do Brasil, em 1964, a televisão, enquanto meio de comunicação, estava em franco processo de solidificação e penetração nos lares brasileiros. À época, sua programação se

Rev. Cad.Comun, Santa Maria, v.20,n.1, art 1, p.1 de 24, jan/abr.2016 
valia de noticiários, folhetins dramáticos e programas humorísticos cujos formatos já eram sucesso no rádio, além da presença constante de artistas populares.

Por conta do apelo popular e fascínio que a televisão exercia sobre seus telespectadores, o governo militar vislumbrou no meio uma forma de ampliar sua hegemonia política e promover a manutenção da ordem e da unidade nacional. Assim, passou a utilizá-la com fins de disseminar e solidificar uma ideia de identidade nacional, segurança e paz social.

Ao lado das marcas estrangeiras, o Estado tornou-se importante anunciante e mantenedor das emissoras aliadas ao regime, investindo recursos que possibilitaram avanços técnicos e tecnológicos, fortalecendo os canais e permitindo o acesso aos satélites, criando a lógica de redes nacionais que perdura até hoje. As redes vinham bem a calhar ao projeto de integração nacional. Além disso, os programas popularescos exibiam artistas ligados à cultura popular, a qual também passava por um momento de industrialização (ORTIZ, 1999).

Ainda sob o intuito da difusão da identidade do brasileiro, as telenovelas dedicavam suas tramas a abordar temáticas vinculadas às regiões distantes dos grandes centros urbanos, difundindo costumes e tradições locais, mas sob a ótica do Sul do país. Esta prática pasteurizou as nuances culturais, as alteridades e peculiaridades, tratando-as do pitoresco ao cômico e mostrando as populações das outras regiões do país como um grupo uniforme, de pessoas incultas, que precisava se modernizar por meio de avanços socioculturais.

Na última metade dos anos 1960, a Organização das Nações Unidas para a Educação, Ciência e Cultura - UNESCO estabeleceu diretrizes voltadas ao desenvolvimento dos países do Hemisfério Sul. Entre estas, havia indicações sobre a difusão urgente de cultura e educação para aqueles que se encontravam à margem da educação formal, o que incluía o uso da televisão no processo educativo. As autoridades brasileiras, guiadas pelo ideal desenvolvimentista e ufanista do governo militar, acreditavam "na ideia da televisão como instrumento educacional, capaz até mesmo de substituir a escola tradicional e seus professores" (CAPPARELLI; LIMA, 2004, p. 125).

Baseadas em tais ideais, algumas experiências de tele-educação foram desenvolvidas, em vários estados, na década de 1960, culminando na criação de emissoras públicas educativas, administradas por órgãos estatais

Rev. Cad.Comun, Santa Maria, v.20,n.1, art 1, p.1 de 24, jan/abr.2016 
ou televisões universitárias, vinculadas ao Ministério da Educação e Cultura-MEC.

Durante os anos 1970, segundo Alexandre Fradkin (2003), vários esforços foram realizados no Brasil, a fim de incrementar a nascente televisão pública do país. Uma delas foi o Programa Nacional de Tele-educação Prontel, criado pelo MEC em 1972, com intuito de coordenar as atividades de videoaulas no país. Nesta mesma década, foi inaugurada a Fundação Centro Brasileiro de TV Educativa - FCBTVE, com finalidade de gerir a Televisão Educativa do Rio de Janeiro - TVE Brasil, cujo objetivo era o de produzir e gerar material para emissoras públicas de outros estados.

Nas décadas seguintes, o Governo Federal desenvolveu diversos projetos no intuito de organizar uma rede nacional que unisse as emissoras públicas do país, a fim de compartilhar conteúdo, suprir carências operacionais e oferecer apoio às emissoras do Norte e Nordeste (FRADKIN, 2003). Dentre estes, talvez um dos mais significativos tenha sido o Sistema Nacional de Radiodifusão Educativa - Sinred, criado em 1983 e administrado pela Fundação Nacional de Televisão Educativa - Funtevê, órgão responsável pela gerência da TVE do Rio.

O objetivo principal do Sinred era o de permitir que todas as emissoras educativas veiculassem uma programação constituída por programas produzidos por todas as integrantes, diferentemente do que ocorria com as redes comerciais, que se limitavam a retransmitir a programação das cabeças-de-rede, localizadas, invariavelmente, no Rio de Janeiro e em São Paulo (FRADKIN, 2003, p.58)

No início dos anos 1990, o Sinred já contava com 15 emissoras afiliadas que, juntamente com a TV Cultura, formavam a Rede Pública de Televisão, tendo sua programação gerada a partir das emissoras do Rio de Janeiro e São Paulo. Tal centralização da produção ocasionava uma grande deficiência na diversificação de conteúdo e na difusão e valorização de elementos e aspectos culturais de outras regiões do país.

Apesar dos esforços empreendidos na criação de uma rede pública de tevê, tais projetos quase sempre esbarraram em sérias deficiências operacionais e financeiras. Somavam-se à falta de investimento, a não existência de políticas públicas sérias, o assédio político governamental e a falta de definição e direcionamento quanto à sua natureza e identidade - algo essencial na formação de uma rede nacional realmente pública, capaz de

Rev. Cad.Comun, Santa Maria, v.20,n.1, art 1, p.1 de 24, jan/abr.2016 
exibir conteúdos diversificados, que valorizassem minorias e identidades regionais. Além disso,

\begin{abstract}
a inexistência de políticas televisivas, somadas à definição social de políticas culturais, o pouco risco e experimentação em suas atividades criativas e de programação, a ausência de produtores independentes que proponham inovações de linguagem, a cópia dos formatos reiterativos das televisões comerciais são apenas alguns dos problemas sofridos pelas televisões públicas e que, em muitos casos, as conduziram infelizmente a uma realidade de prostração e isolamento (MARTÍN-BARBERO E REY, 2001, p. 69).
\end{abstract}

Enquanto parte de um projeto de governo voltado às políticas públicas e sociais, em 2007, foi criada a Empresa Brasil de Comunicação - EBC/TV Brasil, a fim de organizar, juntamente com outros meios públicos, estatais ou universitários, uma rede de dimensão nacional. Tal projeto tem o objetivo de suprir as deficiências dos anteriores, evitando repetir os problemas que conduziram as emissoras públicas do Brasil a um cenário crítico, com pouco orçamento, produções sofríveis e audiência quase nula - com raríssimas exceções, como é o caso de certas fases da TV Cultura.

Desde então, a TV Brasil tem desenvolvido e veiculado conteúdos jornalísticos, culturais, artísticos e esportivos capazes de dialogar com as diferenças regionais do país, bem como com os movimentos sociais, com as minorias e as políticas afirmativas. Tais produções são realizadas pela própria emissora ou por meio de parcerias regionais de coprodução, tanto com tevês locais, quanto com produtores independentes. Os materiais advindos destas coproduções buscam incentivar o pensamento crítico e a cidadania, dialogando com seu público e dando voz à diversidade; dentro dos princípios da televisão de qualidade.

\title{
6. TELEVISÃo PÚBLICA E QUALIDADE DA PROGRAMAÇÃO
}

Muito embora tal debate não seja recente, foi nos anos 1980 que o conceito inicial sobre a qualidade no conteúdo da televisão se desenvolveu dentro dos contextos intelectuais e profissionais britânico e americano - apesar das claras diferenças quanto ao conteúdo e a regulamentação da tevê, nestes dois países. Desde então, o termo quality television, que se refere tanto a questões éticas, sociais e educativas quanto a aspectos

Rev. Cad.Comun, Santa Maria, v.20,n.1, art 1, p.1 de 24, jan/abr.2016 
técnicos e estéticos, passou a ser empregado para definir novas formas de se pensar e fazer tevê.

Nos anos 1930, quando a televisão britânica nasceu, sob o controle do Estado e influência dos setores mais conservadores da sociedade inglesa, já havia um contexto próprio de produção de conteúdo na British Broadcasting Corporation - BBC, cuja rádio já era estatal desde 1927. Este controle inicial levou a emissora a criar uma programação voltada à educação, cultura, interesse público e formação cidadã; valendo-se de um alto padrão estético (LEAL FILHO, 1997).

O controle estatal sobre a BBC manteve a questão da qualidade presente nas discussões e nas produções nacionais desde seu princípio. Leal Filho (1997) aponta que, nas primeiras décadas, o Reino Unido considerava o broadcasting inglês, enquanto patrimônio público e veículo cultural do povo, carecendo assim de proteção das disputas por audiência e das interferências políticas e comerciais.

Nos Estados Unidos, por sua vez, não foram as interferências estatais que conduziram as emissoras à reflexão sobre qualidade na tevê. Segundo Robert J. Thompson (1997), novos desafios, surgidos na década de 1980, acirraram a concorrência entre as televisões americanas, exigindo destas um incremento em suas produções. A multiplicação da oferta de canais, por conta do cabo, e a popularização do videocassete, transformaram as formas de se assistir tevê, trazendo ao debate a questão da segmentação de público e conteúdo, além de abrir as portas do mercado para novas ideias e experimentações.

Mas afinal, o que se pode compreender por televisão de qualidade? De acordo com Thompson (1997), a tevê de qualidade se reconhece por dar visibilidade à diversidade, tratando-se de programas não regulares, que abordem assuntos do cotidiano, com inspiração na realidade e incorporação de elementos que sejam tanto da cultura popular quanto da erudita, ressignificando-as, com apuro estético e diversos pontos de vista.

Embora seja um termo bastante genérico, fica claro, nas discussões sobre qualidade na tevê, que esta pode ser alcançada ao se empregar criatividade e inovação, rompendo com padrões desgastados. Em muitos casos, a criatividade consiste não na geração de algo novo, mas na ressignificação de certas referências e na presença da diversidade, abrangendo, inclusive, minorias e atores sociais excluídos, valorizando e incentivando a manutenção da cultura, tanto a erudita quanto a popular e suas tradições,

Rev. Cad.Comun, Santa Maria, v.20,n.1, art 1, p.1 de 24, jan/abr.2016 
quase sempre ignoradas pelos grandes meios.

Se a televisão é vista como um ritual coletivo, a qualidade pode estar no seu poder de gerar mobilização, participação, comoção nacional em torno de grandes temas de interesse coletivo (...). Outros (...) podem encontrar mais qualidade em programas e fluxos televisuais que valorizem as diferenças, as individualidades, as minorias, os excluídos, em vez da integração nacional e o estímulo ao consumo. Por fim, se é difícil conciliar tantos interesses divergentes, a qualidade pode estar simplesmente na diversidade, o que significa dizer que a melhor televisão seria aquela que abrisse oportunidades para o mais amplo leque de experiências diferenciadas. (MACHADO, 2005, p. 25)

Na América Latina e no Brasil, as discussões acerca da televisão de qualidade são mais recentes e estão vinculadas a estudos culturais e midiáticos, desenvolvidos nos anos 1990, com foco em televisão, audiovisual, mediação e identidade. Apesar disto, alguns conteúdos produzidos pela televisão brasileira, em seus 60 anos de existência, facilmente seriam enquadrados dentro das perspectivas da quality television. Tal condição se deve à concorrência entre as emissoras comerciais, que levou algumas delas a experimentar novas possibilidades estéticas e a implantar padrões técnicos para aferir a qualidade de seus conteúdos. Soma-se a isso o diálogo que tais emissoras mantiveram, principalmente a partir dos anos 1970, com a literatura, teatro e o cinema nacional.

A televisão pública brasileira, apesar dos poucos recursos técnicos e do baixo investimento a que historicamente foi relegada, sempre buscou produzir conteúdos capazes de difundir informação, cultura e entretenimento de qualidade, além de incentivar o senso crítico e a cidadania. Sem compromissos com o lucro ou com anunciantes, a teledifusão pública, embora ainda um conceito em construção, é ambiente ideal para experimentações e desenvolvimento de conteúdos capazes de dar voz à diversidade sociocultural.

Gabriela Borges (2008) desenvolveu um estudo taxionômico e referencial sobre os parâmetros de qualidade no contexto da comunicação pública e suas finalidades culturais, informativas e de entretenimento. De acordo com a autora, além dos paradigmas já reconhecidos como funções típicas de um serviço público de televisão, tais como sua função social, cultural, educativa, política, identitária e informativa, outras características 
são pontuais à televisão pública de qualidade, como as garantias democráticas, mobilização e equilíbrio.

A boa atuação de um canal público de qualidade pode ser aferida por meio de parâmetros sociais e culturais, ao abranger temas de cunho informativo, de construção de valores e comportamento. Borges (2008) define estes parâmetros em três planos: expressão, mensagem audiovisual e conteúdo. Para ela, este último reflete o comprometimento da emissora com a democratização do acesso à arte e conhecimento, incentivo ao debate e estímulo à participação sociocultural; pluralidade de conteúdos; diversidade; fomento, promoção e manutenção de identidades culturais.

Esta claro que muitas características apontadas por Borges (2008) não são exclusividade da televisão pública. Tais condições, por vezes, também podem ser identificadas em produções de caráter comercial. Entretanto, numa emissora pública, por natureza comprometida com a oferta de bons conteúdos aos seus telespectadores, é mais provável a incidência conjunta desses elementos, uma vez que, em relação ao conteúdo, há mais chances de inovação, experimentação, valorização da diversidade e das minorias que na maior parte das emissoras privadas.

\section{A TV BRASIL E A DIFUSÃO DOS DIREITOS HUMANOS}

Apesar dos crescentes debates e exposições midiáticas sobre os direitos humanos, ainda é urgente a carência de espaços democráticos e afirmativos para abordar sua temática. No contexto brasileiro, que conta com uma herança de séculos de distinção social, segregação racial e desrespeito à diversidade, é papel do Estado conduzir o diálogo com as alteridades e implementar políticas públicas que ajudem a superar as desigualdades sociais e que possam assegurar direitos à liberdade e diversidade de expressão, permitindo a livre circulação de informações e opiniões alternativas às que povoam as programações televisuais.

Atendendo a tal demanda, a TV Brasil, criada em 2007, tem sido uma janela para a difusão de conteúdos cidadãos e produções independentes e regionais, dentre as quais estão produções que visam elucidar os pontos da DUDH, apresentar histórias da luta pela redemocratização do Brasil, ou ainda promover o debate sério e afirmativo com a comunidade. 


\subsection{Programa Direitos Humanos}

Produzido pela própria TV Brasil, entre 2013 e 2014, o programa foi desenvolvido com o objetivo de difundir e analisar criticamente a Declaração Universal dos Direitos Humanos, adotada pela Organização das Nações Unidas, em 10 de dezembro de 1948, além de contextualizá-la, por meio de sua aplicabilidade prática no cotidiano. A série conta com 15 episódios, com 26 minutos cada, onde são abordados os 30 itens da DUDH, bem como a história de sua criação.

Em cada episódio, três convidados dividem os espaços de falas, comentando a declaração e respondendo perguntas do público sobre ela. Didático e informativo, um dos pontos-chave do programa é esta participação popular, pois é a partir desta que parte do conteúdo é construída. A fim de elucidar tais questionamentos, entre os convidados encontram-se políticos, juristas, sociólogos e cidadãos.

Para tornar a informação mais acessível e atraente, personalidades de destaque na temática relatam experiências pessoais, em complemento o tema proposto, como, por exemplo, o diretor do Centro de Informação das Nações Unidas no Brasil - Unic Rio, Giancarlo Summa, o jurista e político José Gregori, o idealizador da Comissão Nacional da Verdade e ex-ministro de Direitos Humanos, Paulo Vannuchi, ou o jornalista, sociólogo e geógrafo brasileiro, Demétrio Magnoli, entre outros.

Os episódios de Direitos Humanos foram ao ar a partir de dezembro de 2013, estendendo-se pelo primeiro semestre de 2014, sendo reprisados posteriormente. Seu conteúdo é muito atual, dado o momento de intensas disputas por regulamentações, leis e políticas públicas vivenciados no país, nos últimos anos.

Além dos direitos à vida, educação, saúde, lazer, cultura e moradia, o programa soube trabalhar, de forma eficiente e equilibrada, temas como o matrimônio e a união civil, bem como a liberdade religiosa. Outro ponto alto da série é o episódio que se dispõe a tratar dos sistemas judiciário e penitenciário brasileiros, analisando sua conjuntura e propondo saídas para os diversos problemas enfrentados atualmente por tais aparelhos.

\subsection{Programa Os Advogados Contra a Ditadura}

O programa Os Advogados Contra a Ditadura é uma série composta por cinco episódios, com duração de 52 minutos cada, veiculada pela TV

Rev. Cad.Comun, Santa Maria, v.20,n.1, art 1, p.1 de 24, jan/abr.2016 
Brasil, no primeiro semestre de 2014, tendo sido reapresentado em outras oportunidades. A produção é uma realização da TV Brasil em parceria com o Projeto Marcas da Memória, da Comissão de Anistia do Ministério da Justiça e contou com a direção do documentarista brasileiro Silvio Tendler, conhecido como o "cineasta dos vencidos" ou o "cineasta dos sonhos interrompidos", por abordar, em muitos de seus filmes, personalidades como João Goulart, Juscelino Kubitschek, Carlos Marighella, entre outros.

Além de contar histórias de homens e mulheres que foram fundamentais na luta contra as truculências cometidas pelo Estado, durante a ditadura civil-militar, o programa aponta o papel estratégico dos juristas e presta uma homenagem aos advogados que atuaram na defesa de presos políticos.

A inspiração para a produção foi o livro Advogados e a Ditadura de 1964 - A defesa dos perseguidos políticos no Brasil, organizado pelos professores Fernando Sá, Oswaldo Munteal e Paulo Emílio Martins, lançado em 2010, pela editora PUC-Rio. A ideia do livro, bem como parte de seu conteúdo, foi adaptada para a televisão, valendo-se do formato seriado, o que torna sua exibição mais dinâmica e atraente, além de gerar um documentário, com duas horas e 10 minutos de duração, que também integra o Projeto Marcas da Memória.

Por meio de depoimentos e documentos históricos, a série faz um apanhado do papel estratégico dos advogados que estiveram na defesa de presos políticos, bem como dos processos de construção do projeto Brasil Nunca Mais e da Comissão da Verdade. Diante do recrudescimento da repressão, das leis de segurança e da tortura institucionalizada, os advogados precisaram se posicionar, denunciando as ações do Estado. Ao fazê-lo, tornaram-se também alvos da repressão, das prisões arbitrárias e dos atentados do regime.

Mais que uma justa homenagem a estes personagens, tão importantes no combate às violações dos direitos humanos, durante o Estado de exceção, Os Advogados Contra a Ditadura traz um valioso resgate de um delicado momento da história nacional, importante, enquanto registro, mas também enquanto divulgação, às novas gerações, do que realmente foi tal período. 


\subsection{Programa +Direitos +Humanos}

+Direitos +Humanos é uma série de treze programas, realizada pela TV Brasil, em coprodução com a TVT, TV dos Trabalhadores, de São Bernardo do Campo. Na fase de produção, contou ainda com a colaboração do Instituto Vladimir Herzog, que atuou enquanto consultoria, principalmente na sugestão de pautas e personagens, muito por conta de sua ampla e reconhecida atuação no campo dos direitos humanos.

Realizado em 2014 e veiculado no segundo semestre do mesmo ano, com periodicidade semanal, cada episódio conta com 52 minutos de duração. Com o intuito de ampliar o diálogo com jovens e adolescentes, em muitos casos, carentes de informação de qualidade acerca dos direitos humanos e das minorias, foi utilizado o formato de programa de auditório, a fim de se tornar mais dinâmico e atraente ao seu público-alvo, além de se mostrar mais eficaz no debate equilibrado, onde todas as vozes ganham espaço.

Comandados pelos apresentadores, o cineasta Jeferson De e a atriz Sílvia Lourenço, plateia, convidados e grupos musicais revezam-se na construção do diálogo sobre o tema escolhido para permear o episódio. A direção ficou a cargo dos experientes realizadores audiovisuais Max Alvim e Kiko Goifman.

A série trata, por meio de matérias e entrevistas, da cidadania e diversidade a partir das experiências de jovens, de todas as regiões do Brasil, que atuam em defesa dos direitos humanos, assegurando voz às mulheres indígenas, negros, travestis, prostitutas, surdos, idosos, entre outros, sejam do meio rural ou urbano, do centro ou da periferia, promovendo o diálogo criativo entre as diferentes iniciativas que se encontram para conversar e contar suas histórias.

O intuito é assegurar a liberdade de expressão a grupos que geralmente não teriam espaços para tanto em outros canais, além de servir como uma janela de exibição das ações de ONGs, associações e iniciativas, de várias partes do Brasil, engajadas na garantia de direitos.

\section{CONSIDERAÇÕES}

Diante do quadro de violações dos direitos humanos constantemente praticados pela mídia hegemônica, cabe ao Estado - no seu papel de assegurar os direitos fundamentais a todos os cidadãos, inclusive o do respeito

Rev. Cad.Comun, Santa Maria, v.20,n.1, art 1, p.1 de 24, jan/abr.2016 
pela diferença - fiscalizar e aplicar punições severas a tais empresas, uma vez que as concessões de televisão, no Brasil, são de propriedade pública.

Ainda, cabe também ao Estado abrir espaços afirmativos para o diálogo com a diversidade, valorizando as diferenças identitárias e dando voz às minorias. Como os grandes conglomerados comunicacionais detém o poder econômico e, por consequência, se valem disso para estabelecer forte pressão sobre as decisões políticas, torna-se difícil estabelecer tais janelas nestes meios, ávidos por altos lucros.

Assim, as emissoras públicas de televisão aparecem como alternativa eficaz de veiculação e disseminação de conteúdos afirmativos, independentes, alternativos e regionais, os quais são importantíssimos para a formação de cidadãos mais críticos e conscientes. Os programas mencionados neste trabalho, produzidos e veiculados pela TV Brasil, em 2014, são prova disso.

Tais materiais levaram ao público contextos históricos e sociais de vários movimentos, suas lutas e desafios, inserindo, no debate cotidiano, questões até então consideradas tabus, quando não completamente desconhecidas. Por meio de tais programas, o público pode conhecer, de fato, o que é a Declaração Universal dos Direitos Humanos e seus reais intentos. Pode ainda ouvir e mesmo questionar os movimentos negro, LGBT, feministas e de outras minorias e excluídos, além de mergulhar num momento histórico importantíssimo para o debate sobre os direitos humanos, no Brasil: os tenebrosos anos da ditadura civil-militar.

Embora o desafio da formação e educação em direitos humanos ainda seja enorme, num país repleto de desigualdades econômicas, sociais e educativas como o Brasil, tais conteúdos veiculados pela televisão pública podem apontar caminhos interessantes e modelos a serem seguidos, cooperando para produzir profundas transformações no imaginário social e, consequentemente, nas práticas cotidianas da sociedade brasileira.

\section{REFERÊNCIAS}

BARBOSA, Silvio Henrique Vieira. TV e cidadania. São Paulo: All Print, 2010.

BORGES, Gabriela. Parâmetros de qualidade para a análise de programas televisivos de âmbito cultural: uma proposta teórico-metodológica. Revista Nau - NP em Comunicação Audiovisual da Intercom, 01 (01):173-192, 2008.

Rev. Cad.Comun, Santa Maria, v.20,n.1, art 1, p.1 de 24, jan/abr.2016 
BOURDIEU, Pierre. Sobre a televisão. Rio de Janeiro: Jorge Zahar, 1997.

BUCCI, Eugênio. Como a violência na TV alimenta a violência real - da polícia. In: BUCCl, Eugênio; KEHL, Maria Rita. Videologias: ensaios sobre televisão. São Paulo: Boitempo, 2004.

CAPPARELLI, Sérgio; LIMA, Venício Artur de. Comunicação e televisão: desafios da pós-globalização. São Paulo: Hacker, 2004.

FRADKIN, Alexandre. Histórico da TV pública / educativa no Brasil. In: CARMONA, Beth (Org.). O desafio da TV pública: uma reflexão sobre sustentabilidade e qualidade. Rio de Janeiro: TVE Rede Brasil, 2003.

KEHL, Maria Rita. Televisão e violência do imaginário. In: BUCCI, Eugênio; KEHL, Maria Rita. Videologias: ensaios sobre televisão. São Paulo: Boitempo, 2004.

LEAL FILHO, Laurindo. A melhor TV do mundo. São Paulo: Summus, 1997.

LUSVARGHI, Luiza. De MTV a Emetevê: Pós-modernidade e cultura mcworld na televisão brasileira. São Paulo: Editora de Cultura, 2007.

MACHADO, Arlindo. A televisão levada a sério. São Paulo: Senac SP, 2005.

MARTÍN-BARBERO, Jesús; REY, Germán. Os exercícios do ver: hegemonia audiovisual e ficção televisiva. São Paulo: Senac SP, 2001.

MATTOS, Sérgio. A televisão no Brasil: 50 anos de história (1950 - 2000). Salvador: Editora PAS; Ianamá, 2000.

MIRA, Maria Celeste. O moderno e o popular na TV de Sílvio Santos. In: RIBEIRO, Ana Paula Goulart; SACRAMENTO, Igor; ROXO, Marco. (Orgs.). História da televisão no Brasil. São Paulo: Contexto, 2010.

MOURA, Iara. Guia mídia e direitos humanos. São Paulo: Intervozes, 2014.

ORTIZ, Renato. A moderna tradição brasileira. São Paulo: Brasiliense, 1999.

Rev. Cad.Comun, Santa Maria, v.20,n.1, art 1, p.1 de 24, jan/abr.2016 
CADERNOS DE COMUNICAÇÃO

UNIVERSIDADE FEDERAL DE SANTA MARIA

ROXO, Marco. A volta do jornalismo cão na TV. In: RIBEIRO, Ana Paula Goulart; SACRAMENTO, Igor; ROXO, Marco. (Orgs.). História da televisão no Brasil. São Paulo: Contexto, 2010.

THOMPSON, Robert J. Television's second golden age: from Hill Street Blues to ER. Syracuse, New York: Syracuse University Press, 1997. 


\title{
Waldelio Pinheiro do Nascimento Júnior
}

\begin{abstract}
Jornalista (UESB), mestre em Comunicação e Culturas Midiáticas (UFPB) e doutorando em Educação (UFPB). Pesquisador associado à Intercom e à Rede Folkcom, estuda comunicação contra-hegemônica, cultura popular e movimentos sociais. É diretor de imagens na TV UFPB e professor da graduação em Relações Públicas, na UFPB.
\end{abstract}

RECEBIDO EM: 01/05/2016

APROVADO PARA PUBLICAÇÃO: 20/05/2016 